\title{
STUDI DESKRIPTIF PENERAPAN PENDIDIKAN KARAKTER ANAK TUNAGRAHITA SEDANG DI SEKOLAH DASAR LUAR BIASA
}

\author{
Galih Dwiana Putra \\ SDLB Banyumas, Banyumas, Indonesia \\ galihpoetra@yahoo.com
}

\begin{abstract}
Character education is not only applied in public schools, but also for special schools with students who have special needs. This study aims to find out: (1) Application of honest character education discipline and responsibility for children with mental retardation in Banyumas Elementary School (2) Obstacles in the implementation of character education for mentally retarded children in SDLB Banyumas (3) Solutions to overcome obstacles in the application of education the character of mentally retarded children is at the Banyumas Primary School. This research was conducted at the Banyumas Elementary School. This research uses a descriptive method with data collection techniques through interviews, observation, and documentation study. Participants in the study were Principals, Teachers, Parents of moderate mentally retarded children, and Students with a classification of moderate retardation children. The results of the study are as follows: 1) The application of character education at the Banyumas Elementary School has been going well. This can be seen from the strategies and media of learning carried out by the teacher in applying character values. 2) Obstacles in the application of character education in Banyumas Elementary School are from aspects of physical characteristics, psychological characteristics, social characteristics, and aspects of parents or family. 3) Solutions to overcome obstacles in the application of character education, among others: the use of appropriate learning strategies supported by the learning media used, therapeutic classes, working with psychologists to determine children's abilities, and also the direction or understanding of the school to parents of students. Based on the results of the study, it can be concluded that the application of character education at the Banyumas Elementary School has been going well. It can be assessed from the success of the school in implementing character education from the stages of socialization, planning, implementation, evaluation, development, and learning strategies used by the teacher. To overcome the obstacles, the solution that the school takes is to work together with a psychologist and also hold a guardian meeting with the parents of students.
\end{abstract}

\section{Keywords: character education, mentally retarded children, SDLB}

Abstrak. Pendidikan karakter tidak hanya diterapkan di sekolah umum saja, tetapi juga untuk sekolah khusus dengan siswa yang mempunyai kebutuhan khusus. Penelitian ini bertujuan untuk mengetahui: (1) Penerapan pendidikan karakter jujur disiplin dan tanggung jawab bagi anak tunagrahita sedang di SDLB Banyumas (2) Kendala dalam penerapan pendidikan karakter anak tunagrahita sedang di SDLB Banyumas (3) Solusi yang dilakukan untuk mengatasi kendala dalam penerapan pendidikan karakter anak tunagrahita sedang di SDLB Banyumas. Penelitian ini dilaksanakan di SDLB Banyumas. Penelitian ini menggunakan metode deskriptif dengan teknik pengumpulan data melalui wawancara, observasi, dan studi dokumentasi. Partisipan dalam penelitian adalah Kepala Sekolah, Guru, Orang tua anak tunagrahita sedang, dan Siswa dengan klasifikasi anak tunagrahita sedang. Hasil penelitian adalah sebagai berikut: 1) Penerapan pendidikan karakter di SDLB Banyumas sudah berjalan baik. Hal itu dapat dilihat dari strategi dan media pembelajaran yang dilakukan oleh guru 
dalam menerapkan nilai-nilai karakter. 2) Kendala dalam penerapan pendidikan karakter di SDLB Banyumas adalah dari aspek karakteristik fisik, karakteristik psikis, karakteristik sosial, dan dari aspek orang tua atau keluarga. 3) Solusi untuk mengatasi kendala dalam penerapan pendidikan karakter yaitu antara lain: penggunaan strategi pembelajaran yang sesuai dengan didukung oleh media pembelajaran yang digunakan, adanya kelas terapi, bekerja sama dengan psikolog untuk mengetahui kemampuan anak, dan juga adanya arahan atau pengertian dari pihak sekolah kepada orang tua siswa. Berdasarkan hasil penelitian, maka dapat disimpulkan bahwa penerapan pendidikan karakter di SDLB Banyumas sudah berjalan baik. Hal itu dapat dinilai dari keberhasilan sekolah dalam menerapkan pendidikan karakter dari tahap sosialisasi, perencanaan, pelaksanaan, evaluasi, pengembangan, serta strategi pembelajaran yang digunakan oleh guru. Untuk mengatasi kendala, solusi yang dilakukan sekolah yaitu mengadakan kerja sama dengan psikolog dan juga mengadakan rapat wali murid dengan orang tua siswa.

\section{Kata Kunci: Pendidikan karakter, tunagrahita sedang, SDLB}

\section{LATAR BELAKANG}

Pendidikan pada dasarnya untuk mengembangkan sumber daya manusia yang berkualitas. Pendidikan membentuk kepribadian peserta didik akan pentingnya nilai-nilai dalam bermasyarakat, berbangsa dan bernegara. Perubahan perilaku yang sesuai dengan aturan adalah tolak ukur keberhasilan dari pendidikan yang berkarakter. Pentingnya pendidikan karakter bangsa tercantum dalam UndangUndang RI Nomor 20 Tahun 2003 tentang Sistem Pendidikan Nasional (UUSPN) yaitu pendidikan nasional berfungsi mengembangkan kemampuan dan membentuk watak serta peradaban bangsa yang bermartabat dalam rangka mencerdaskan kehidupan bangsa, bertujuan untuk berkembangnya potensi peserta didik agar menjadi manusia yang beriman dan bertakwa kepada Tuhan Yang Maha Esa, berakhlak mulia, berilmu, cakap, kreatif, mandiri, dan menjadi warga negara yang demokratis serta bertanggung jawab. Melihat dan menimbang pentingnya pendidikan karakter, maka harus ditanamkan secara serius kepada generasi penerus bangsa.

Pendidikan karakter harus ditanamkan secara serius kepada generasi penerus bangsa. Fenomena permasalahan perilaku yang tidak sesuai dengan nilainilai karakter saat ini sudah mulai terlihat. Lickona (2013: 15) menyatakan bahwa perilaku yang tidak sesuai dengan nilai karakter sebagai contoh meningkatnya kekerasan di kalangan remaja/masyarakat, mencuri, curang, kekejaman dengan teman sebaya, kefanatikan, bahasa yang kasar, rendahnya rasa tanggung jawab individu dan kelompok, membudayanya kebohongan/ketidakjujuran, meningkatnya perilaku merusak diri seperti penggunaan narkoba, alkohol, dan seks bebas, serta semakin rendahnya rasa hormat kepada orang tua dan guru.

Melihat dari fenomena yang terjadi saat ini, maka pemerintah membuat peraturan tentang penerapan pendidikan karakter. Peraturan undang-undang mengenai pendidikan karakter yang dibuat oleh pemerintah harus diterapkan secara merata di sekolah khususnya sekolah formal. Pendidikan formal bukan hanya diselenggarakan untuk anak berkategori saja, tetapi juga untuk anak luar biasa. Hak pendidikan bagi anak luar biasa juga tercantum dalam Konferensi Dunia tentang Pendidikan bagi Anak Luar Biasa pada tanggal 7-10 Juni 1994 yaitu di Salamanca, Spanyol. Hasil dari deklarasi Salamanca dimantapkan komitmen tentang Education for All dan dikeluarkan kerangka kerja untuk Pendidikan Anak Luar Biasa. Kerangka kerja dalam deklarasi Salamanca tersebut diantaranya yaitu setiap anak mempunyai hak yang fundamental untuk mendapatkan pendidikan, setiap anak mempunyai karakteristik yang unik, dan 
sekolah yang berorientasi pada kebutuhan yang sesuai dengan karakteristik anak merupakan sarana efektif untuk melawan sikap diskriminatif, dan menciptakan masyarakat yang mau menerima kedatangan anak luar biasa (Wardani dkk, 2009: 1.35).

Rumusan masalah dalam penelitian ini adalah: 1) Bagaimana penerapan pendidikan karakter di Sekolah Dasar Luar Biasa C (SDLB-C). 2) Apakah kendala yang dihadapi guru dalam penerapan pendidikan karakter. 3) Bagaimana solusi yang dilakukan untuk mengatasi kendala dalam penerapan pendidikan karakter.

Tujuan dari penelitian ini adalah: 1) Mengetahui bagaimana penerapan pendidikan karakter di Sekolah Dasar Luar Biasa C (SDLB-C). 2) Mengetahui kendala yang dihadapi guru dalam penerapan pendidikan karakter. 3) Mengetahui solusi yang dilakukan untuk mengatasi kendala dalam penerapan pendidikan karakter.

Pelaksanaan pendidikan karakter di satuan pendidikan perlu melibatkan seluruh warga sekolah, orangtua siswa dan masyarakat sekitar. Menurut Daryanto dan Darmiatun (2013: 78), strategi dalam pelaksanaan pendidikan karakter yaitu melalui tahap sosialisasi, tahap perencanaan, tahap pelaksanaan, tahap evaluasi, dan tahap pengembangan.

Pendidikan karakter tidak hanya diterapkan di sekolah umum saja, namun juga diterapkan di sekolah luar biasa. Sekolah Luar Biasa (SLB) adalah sekolah yang dirancang khusus untuk anak-anak yang mempunyai keterbatasan atau kebutuhan khusus. Menurut Heward (Dedy dan Yani, 2013: 28) anak berkebutuhan khusus adalah anak dengan karakteristik yang berbeda dengan anak pada umumnya tanpa selalu menunjukkan pada ketidakmampuan mental, emosi atau fisik. Menurut Somantri Sutjihati (2012: 103) mengatakan bahwa seseorang dikategorikan berkelainan mental sub normal atau tunagrahita adalah kondisi anak yang kecerdasannya jauh dibawah rata-rata dan ditandai oleh keterbatasan inteligensi dan ketidakcakapan dalam interaksi sosial yang mengakibatkan sukar untuk mengikuti program pendidikan secara umum dan membutuhkan layanan pendidikan secara khusus yaitu disesuaikan dengan kemampuan anak.

Pada umumnya masyarakat merasa asing dengan anak tunagrahita, bahkan anak tunagrahita sering dianggap sebagai orang gila. Hal tersebut menyebabkan dampak bagi keluarga. Menurut Somantri Sutjihati (2012: 117) mengatakan bahwa orang yang paling banyak menanggung beban akibat ketunagrahitaan adalah orang tua dan keluarga anak tersebut. Menurut Somantri Sutjihati (2012: 118) menjelaskan bahwa perasaan dan tingkah laku orang tua berbeda-beda dan dapat dibagi menjadi: perasaan melindungi secara berlebihan, adanya perasaan bersalah melahirkan anak berkelainan, kehilangan kepercayaan akan mempunyai anak yang normal, terkejut dan kehilangan kepercayaan diri, kemudian berkonsultasi untuk mendapatkan berita-berita yang baik, merasa bingung dan malu, sehingga menyebabkan orang tua kurang suka bergaul dengan tetangga dan lebih suka menyendiri.

\section{METODE PENELITIAN}

Penelitian ini menggunakan metode penelitian deskriptif kualitatif. Penelitian ini dilaksanakan di Sekolah Dasar Luar Biasa (SDLB-C) di Kecamatan Banyumas. Wawancara dalam penelitian ini dilaksanakan dengan menggunakan teknik purposive sampling terhadap 9 narasumber. Narasumber yang diwawancarai dengan nama inisial yaitu TB, URD, MY, DK, ER, SJ, R, QR, dan SA. Partisipan penelitian dalam penelitian ini menggunakan koding sebagai berikut: 
Tabel 1.

Koding Partisipan Penelitian

\begin{tabular}{|l|l|l|l|}
\hline No & \multicolumn{1}{|c|}{ Inisial } & \multicolumn{1}{c|}{ Jabatan } & \multicolumn{1}{c|}{ Koding } \\
\hline 1. & TB & Kepala Sekolah & TB/KS1 \\
\hline 2. & URD & Guru Kelas & URD/GR2 \\
\hline 3. & MY & Guru Kelas & MY/GR3 \\
\hline 4. & DK & Guru Kelas & DK/GR4 \\
\hline 5. & ER & Guru Kelas & ER/GR5 \\
\hline 6. & SJ & Guru Kelas & SJ/GR6 \\
\hline 7. & R & Orang tua siswa & R/OT1 \\
\hline 8. & SA & Orang tua siswa & S/OT2 \\
\hline 9. & QR & Siswa & Q/S1 anak \\
\hline
\end{tabular}

Dalam penelitian kualitatif teknik pengumpulan data dilakukan dengan observasi, wawancara dan penelaahan dokumen dalam pengambilan datanya (Sugiyono, 2013: 62). Analisis data dalam penelitian kualitatif ini menggunakan teknik analisis dari Miles and Huberman (Sugiyono, 2013: 337). Data yang diperoleh akan direduksi kemudian disajikan untuk selanjutnya penarikan kesimpulan.

\section{HASIL PENELITIAN DAN PEMBAHASAN}

Berdasarkan hasil temuan yang dilakukan peneliti di SDLB Banyumas bahwa penerapan pendidikan karakter di SDLB Banyumas dilakukan dalam lima tahap, yaitu: tahap sosialisasi, tahap perencanaan, tahap pelaksanaan, tahap evaluasi, dan tahap pengembangan. Hal tersebut sesuai dengan teori dari Daryanto dan Darmiatun (2013: 78) yang menjelaskan bahwa strategi dalam pelaksanaan pendidikan karakter dilakukan melalui tahap sosialisasi, perencanaan, pelaksanaan, evaluasi, dan tahap pengembangan. Berdasarkan hasil observasi dan wawancara, dalam penerapan pendidikan karakter nilai kejujuran, tanggung jawab, dan disiplin siswa, guru mempunyai kedala. Menurut Mumpuniarti (2007: 25) karakteristik pada aspek individu anak tunagrahita terbagi dalam karakteristik fisik, karakteristik psikis, dan karakteristik sosial. Pada karakteristik fisik, guru mengalami kendala yaitu pada postur fisik anak tunagrahita berkebutuhan khusus lainnya. Hal ini menyebabkan anak mendapatkan disriminasi dan stigma dari lingkungan yang berpengaruh pada aspek psikis anak. Kemudian kendala pada aspek psikis yaitu anak tunagrahita kurang dalam konsentrasi, respon yang lamban, kemudian karakter anak yang pendiam ataupun sebaliknya yaitu hiperaktif.

Hal tersebut sejalan dengan Somantri Sutjihati (2012: 103) yang menyatakan bahwa seseorang dikategorikan berkelainan mental sub normal atau tunagrahita adalah kondisi anak yang kecerdasannya jauh dibawah rata-rata dan ditandai oleh keterbatasan inteligensi dan ketidakcakapan dalam interaksi sosial yang mengakibatkan sukar untuk mengikuti program pendidikan secara umum dan membutuhkan layanan pendidikan secara khusus yaitu disesuaikan dengan kemampuan anak.

Kendala dari aspek karakteristik sosial pada anak tunagrahita yaitu anak memiliki sikap sosial yang kurang baik, rasa etis yang kurang, tidak mempunyai rasa terima kasih, rasa belas kasihan, dan rasa keadilan. Hal ini ditunjukkan dalam sikap sosial keseharian anak. Kendala dari aspek karakteristik orang tua yaitu pemahaman orang tua terhadap keterbatasan anak tunagrahita. Orang tua menginginkan atau menuntut anak agar dapat membaca, menulis, tetapi orang tua tidak memahami keterbatasan yang dimiliki anak. Hal ini sesuai dengan Somantri Sutjihati (2007: 118) yang menyatakan bahwa terdapat perasaan dan 
tingkah laku yang berbeda-beda dari orang tua dalam menanggapi keterbatasan yang dimiliki anaknya. Kemudian kendala dari orang tua yang lainnya yaitu orang tua yang sudah lelah untuk mengantar anak dan mempunyai kegiatan lain, sehingga dalam kedisiplinan anak kurang. Selain itu juga pendidikan orang tua sangat berpengaruh dalam penerapan pendidikan karakter anak.

Solusi untuk mengatasi kendala dari aspek orang tua yaitu baik dari guru maupun pihak sekolah memberikan pengertian kepada orang tua dengan diadakannya rapat wali murid, dan juga rapat dewan guru antara kepala sekolah dengan guru. Hal ini bertujuan agar dapat menemukan solusi bersama dalam menangani kendala. Hal tersebut sesuai dengan teori dari Hallahan \& Kauffman (Mumpuniarti: 2007) yang menyatakan bahwa layanan pendidikan untuk anak tunagrahita adalah terdiri dari program pra sekolah dan program kelas dasar dan lanjutan. Pada program pra sekolah memerlukan adanya dukungan Speech Therapy dan Physical Therapy, dan orang tua dari anak yang lebih banyak terlibat untuk melatihnya.

\section{A. SIMPULAN DAN SARAN}

Berdasarkan hasil penelitian dan pembahasan pada bab IV mengenai penerapan pendidikan karakter, kendala yang dialami, dan solusi yang dilakukan dalam mengatasi kendala penerapan pendidikan karakter di SDLB Banyumas, maka dapat disimpulkan sebagai berikut:

1.Penerapan pendidikan karakter di SDLB Banyumas dilaksanakan melalui tahap sosialisasi, perencanaan, pelaksanaan, evaluasi, dan pengembangan.

2. Kendala dalam penerapan pendidikan karakter di SDLB Banyumas dibagi dalam empat hal yaitu berdasarkan karakteristik aspek fisik, karakteristik aspek psikis, karakteristik aspek sosial, dan karakteristik aspek orang tua. Berdasarkan karakteristik aspek fisik kendala yang dihadapai yaitu postur tubuh dari anak tunagrahita sedang yang berbeda dengan anak berkebutuhan khusus lainnya menyebabkan diskriminasi dan stigma dari masyarakat. Hal ini berpengaruh dalam kondisi psikis anak tunagrahita sedang. Kemudian kendala dari aspek fisik lainnya yaitu dari penglihatan dan kemampuan motorik. Untuk kendala pada aspek psikis adalah anak nampak hampir tidak mempunyai rasa inisiatif, kekanak-kanakan, sering melamun atau sebaliknya hiperaktif, kurangnya konsentrasi, dan respon yang lamban dalam menerima perintah. Pada aspek sosial, kendala yang dihadapi adalah anak tunagrahita sedang memiliki sikap sosial yang kurang baik, rasa etis yang kurang, tidak mempunyai rasa terima kasih, rasa belas kasihan, dan rasa keadilan. Kemudian pada aspek keluarga atau orang tua, kendala yang dihadapi adalah tidak ada yang mengantar anak berangkat ke sekolah, orang tua mengurus anggota keluarganya terlebih dahulu, orang tua ada acara atau sakit, jarak yang jauh sehingga malas untuk berangkat ke sekolah dan pemahaman orang tua terhadap keterbatasan kemampuan anaknya, serta pendidikan orang tua dalam penerapan pendidikan karakter untuk anak.

3. Solusi untuk mengatasi kendala dalam penerapan pendidikan karakter di SDLB Banyumas adalah menggunakan strategi pembelajaran yang mendukung penanaman pendidikan karakter seperti penggunaan jadwal sholat, kamus SIBI. Untuk kendala kemampuan anak tunagrahita, solusinya adalah dengan memberikan pengertian dan pengarahan setiap hari kepada anak. Kemudian adanya rujukan dari psikolog dan adanya kelas terapi. Selanjutnya, untuk kendala dari pemahaman orang tua, baik dari guru maupun pihak sekolah saling memberikan pengertian, diadakannya rapat wali murid antara guru dengan wali murid, dan juga rapat dewan guru antara kepala sekolah dengan guru. Hal ini bertujuan agar dapat menemukan solusi bersama dalam menangani kendala yang dihadapi masing-masing guru. 
Berdasarkan hasil penelitian tentang penerapan pendidikan karakter di SDLB Banyumas, peneliti mencoba mengemukakan saran. Saran ini diharapkan dapat membantu memberikan masukan kepada pihak terkait.

1. Bagi Guru

a. Guru harus dapat menggunakan metode pembelajaran yang menarik yang sesuai dengan kemampuan siswa.

b. Guru harus dapat memahami kondisi setiap siswa, karena setiap siswa memiliki kemampuan yang berbedabeda.

c. Guru harus selalu memberikan perhatian kepada siswa dalam pelaksanaan pembelajaran.

2. Bagi Siswa

a. Siswa harus dapat mengikuti peraturan atau tata tertib di sekolah dengan baik.

b. Siswa harus dapat mengikuti pembelajaran dengan baik di sekolah guna membentuk sikap sesuai dengan nilai-nilai karakter bangsa.

c. Siswa dapat menerapkan nilai-nilai karakter bangsa tidak hanya di sekolah tetapi juga di lingkungan rumah.

3. Bagi Sekolah

a. Sekolah diupayakan dapat menciptakan suasana yang mendukung dalam penerapan pendidikan karakter, sehingga proses pembentukan nilai-nilai karakter kepada siswa lebih maksimal lagi.

b. Sekolah diupayakan dapat memaksimalkan setiap ruangan kelas, seperti ruang kegiatan bina diri dan juga ruang seni musik. Hal tersebut bertujuan agar dapat lebih memaksimalkan pembelajaran untuk menerapkan nilai-nilai karakter kepada siswa.

4. Bagi Orang Tua

Orang tua diharapkan dapat lebih memahami kemampuan anaknya, sehingga orang tua dapat memahami apa yang dibutuhkan oleh anaknya dan dapat mendukung setiap kegiatan anak

\section{DAFTAR PUSTAKA}

Daryanto dan Darmiatun.(2013). Implementasi Pendidikan Karakter di Sekolah. Yogyakarta: Gava Media.

Lickona, Thomas.(2013). Pendidikan Karakter: Panduan lengkap mendidik siswa menjadi pintar dan baik. Bandung: Nusa Media

Mumpuniarti.(2007). Pembelajaran Akademik Bagi Tunagrahita. Yogyakarta: FIP UNY

Somantri, Sutjihati.(2012). Psikologi Anak Luar Biasa. Bandung: Refika Aditama.

Sugiyono.(2013). Metodologi Penelitian Kualitatif. Bandung: Alfabeta.

Wardani,dkk.(2009). Pengantar Pendidikan Luar Biasa. Jakarta: Universitas Terbuka 